been welcomed by Canada's Science Council, which has recently been arguing that such moves are necessary to promote the country's technological autonomy. "We are delighted with the new tax incentives, particularly those for small businesses, which tend to be an important source of industrial innovation, and where Canadian ownership is concentrated", the council's executive director, Mr John Shepherd, said last week.

Members of the scientific community, however, while welcoming the Government's commitment, are concerned that too much emphasis may be placed on relatively short-term research objectives, with a corresponding neglect of more long-range, basic research. And widespread concern was expressed in September when it was announced that a number of areas of federallysponsored research would be cut back as part of a package of austerity measures.

The effect of the cuts, which included closing down a number of internationally recognised government research stations, has been to reduce the $1979 / 1980$ research budgets of the
Department of Agriculture by $\$ 3.5$ million, of Energy by $\$ 11.7$ million, and of Fisheries by $\$ 11.1$ million.

Budget increase of $\$ 5$ million for the Natural Sciences and Engineering Research Council and $\$ 3$ million for the Medical Research Council, announced by $\mathrm{Mr}$ Buchanan in June will remain relatively intact, with only $\$ 500,000$ being taken away from each. However a $\$ 2$ million reduction in the budget of the National Health Research and Development programme will mean the termination of several health care research programmes.

The Canadian Association of University Teachers and other universitybased organisations have sent a telegram to Mr Trudeau warning him of the "disastrous" implications of the cuts for higher education, research and health care.

Public expressions of concern have not been without their effect. Last month the Government reversed its decision to close one of the oldest research stations in Canada, that attached to an experimental forest at Petawawa, Ontario; following considerable outcry, it has been agreed to keep the research station open, and to amalgamate into it two research groups currently based in Ottawa, namely the Forest Fire Research Institute and the Forestry Management Research Institute.

Nor has a number of universities been slow to realise that the future survival of their research efforts may depend on the extent to which they can build up a working relationship with both government and industry. This week, a two-day conference bringing together leading representatives of the three constituencies to work out mechanisms for co-operation is being held in Saskatoon, an event which some observers feel would have gained little support 10 years ago.

The scientific community must do more than simply complain about reductions in budget expenditures, says Dr John Kucharcyzk of the CFBS, which has organised the conference. "Instead we must continue to stress the importance of a vigorous scientific effort to reach Canada's overall economic objectives."

David Dickson

\title{
NASA plans a new Venus mission
}

As us scientists prepare to analyse the data from the four probes that began their descent through the atmosphere of Venus this week, the National Acronautics and Space Administration is already working on plans for a follow-up mission to the planet.

The current Pioneer Venus mission is primarily concerned with sending back data on the atmosphere of Venus. In contrast the new mission, which NASA hopes President Carter will include in his budget request to Congress for the fiscal year 1980 , would gather detailed information about the planet's surface and its internal structure.

The proposed Venus mission is at present top of NASA's priority list for new projects in the planetary sciences. Close behind is a project. scheduled for possible inclusion in the 1981 budget, to send a spacecraft past Halley's Comet as it approaches the sun in 1985 and on to an encounter with the Comet Tempel 2.

Both missions are expected to cost between $\$ 300$ and $\$ 500$ million, and are within the framework of the US Administration's policy for space science announced two months ago. In a "normal" year. NASA officials feel the new Venus mission would stand a high chance of being financed; but with the country in a cost-cutting mood, it remains to be seen whether NASA's request survives the budget process.

The new mission is known as the Venus Orbiting Imaging Radar (VOIR), and would involve a spacecraft circling the planet for at least seven months, providing the first detailed global view of its surface.

In the current mission, Pioneer Venus 1 will orbit the planet, and send back radar pictures. Their resolution, however. will not be much better than that which can already be obtained from Earth. The Soviet Venera missions have already sent back pictures transmitted from the surface of the planet. but only from three fixed locations.

The new spacecraft would, if it receives approval, be launched in December 1984 to arrive at the planet in May 1985. Radar mapping of the surface will be carried out using the synthetic aperture radar (SAR) successfully tested on the ill-fated Seasat mission; this will provide nearglobal coverage of the planet in moderate resolution, and coverage of a pre-selected small percentage of the planet's surface in high resolution (down to about 50 metres).

In addition to the SAR, the VOIR orbiter will also carry an altimeter and a magnetometer. It is hoped that the spacecraft will disclose the presence $\mathrm{r}$ absence of continents, ocean basins, volcanoes and other geophysical phenomena, as well as the nature and time sequence of any plate tectonic activity.

The proposed mission to the Comet Temool 2. which circles the sun once every five years, follows the abandonment last year of more ambitious plans for a close-range study of Halleys Comet, a mission for which NASA reluctantly decided it would have been too expensive to develop an appropriate propulsion system.

Part of the problem is that Halley's Comet circles the sun in an opposite direction from the earth, and a close encounter would have involved elaborate manoeuvring. The new plan is for a spacecraft propelled by the ionisation of mercury vapour to be launched on a course that passes close to the comet, dropping a probe into its tail, and then continues to a position that would allow it to travel alongside Comet Tempel 2 three years later.

Other projects submitted by NASA to the White House for possible inclusion in the 1980 budget include a gamma-ray observatory designed to study, for example. the high energy nuclear and gravitational nrocesses which occur in the vicinity of neutron stars and black holes: an an advanced X-ray atrophysics facility which will provide high resolution data on the position and structure of celestial objects such as pulsars, binary-star systems, and quasars.

David Dickson 